\title{
EL CONCEPTO DE CONCIENCIA CARTESIANO Y LA OBJECIÓN DEL REGRESO AL INFINITO DE PENSAMIENTOS
}

\author{
PEDRO STEPANENKO GUTIÉRREZ \\ INSTITUTO DE INVESTIGACIONES FILOSÓFICAS \\ Universidad Nacional AutónOMa dE MÉxico
}

El presente trabajo intenta ofrecer una interpretación de la conciencia en la filosofía cartesiana tal, que permita evitar la objeción de un regreso al infinito de pensamientos, a la cual se enfrenta la siguiente afirmación de Descartes: "no puede haber en nosotros pensamiento alguno, del cual no tengamos conciencia en el momento mismo en que se da en nosotros". ${ }^{1}$

La objeción del regreso al infinito de pensamientos se le presentó a Descartes ya en las terceras (de Hobbes) y en las sextas objeciones a las Meditaciones metafísicas, sólo que en ellas no apunta en contra de la afirmación arriba citada, sino en contra de la formulación del cogito.

El pasaje de Hobbes reza así:

No es mediante otro pensamiento por el que infiero que pienso, pues, aun cuando alguien pueda pensar que pensó, lo cual no es más que un recuerdo, sin embargo, es absolutamente imposible pensar que se piensa o saber que se sabe. Sería una interrogación al infinito: ¿de dónde sabes que sabes que sabes que sabes? ${ }^{2}$

El contexto en el cual se encuentra este pasaje es la reflexión siguiente: de la proposición "pienso" debe seguirse que "la cosa pensante es algo

1 AT, VI, p. 246; AT, IX, p. 190; p. 198 (Alf.). Las citas de las obras de Descartes las he traducido yo mismo basándome, en el caso de las Meditaciones metafisicas, de donde provienen la mayoria, en la traducción de Vidal Peña (Meditaciones metafísicas con objeciones y respuestas, Ediciones Alfaguara, Madrid, 1977). Dado que la versión francesa de las Meditaciones metafísicas, en la cual se apoya fundamentalmente Vidal Peña, difiere de la latina en puntos importantes, he introducido modificaciones en todos los casos. Por ello doy la referencia de la versión latina y de la francesa en la edición de Adam y Tannery (AT), así como de la traducción al español de Vidal Peña (Alf.).

2 AT, VII, p. 173; AT, IX, p. 135; p. 141 (Alf.). 
corpóreo; pues parece ser que los sujetos de toda acción sólo pueden entenderse como corpóreos o materiales". ${ }^{3}$ Así expuesto el asunto, no queda claro cómo Hobbes pretende apoyar esta opinión mediante la objeción antes citada, sin embargo la objeción misma está justificada, en la medida en que para aceptar el cogito tenemos que exigir la conciencia de que pienso como simultánea a la proposición "pienso", y esto, porque en el momento en que aparece el cogito la memoria ha quedado suspendida. Si ahora llamamos "pensamiento" a esta conciencia, tenemos que aceptar que el cogito exige pensar que pienso. O bien, si llamamos al pensar que pienso "saber", entonces el cogito nos orilla a aceptar el saber que sé.

Kenny, Curley y Kemmerling han creído encontrar la respuesta de Descartes a esta objeción ${ }^{4}$ de un regreso "amenazante" en el siguiente texto:

Y no sirve de nada, como lo hace este filósofo aquí, decir que un pensamiento no puede ser sujeto de otro pensamiento. Nadie más que él ha fingido que eso sea así. ${ }^{5}$

Esto no es más que un malentendido. Descartes no quería decir aquí: "no one but Hobbes had ever imagined that one thought could be the topic of another thought", 6 como lo han interpretado estos autores. Por la palabra subjectus debe entenderse aquí sustancia. Esto queda claro, si tomamos en consideración la objeción completa, en la que Hobbes inserta como complemento el regreso al infinito de pensamientos. En la primera parte Hobbes opina que hablar de un espíritu, un entendimiento o una razón, significa tomar por un sujeto lo que es una facultad o una acción. "El señor Descartes, entonces, considera que son lo mismo el que entiende y la intelección, que es acto suyo; o, al menos, dice ser lo mismo la cosa que entiende y el entendimiento, que es una facultad o potencia de la cosa que entiende. Sin embargo, todos los filósofos hacen distinción entre, de una parte, el sujeto, y de otra, sus facultades y actos." En la segunda parte Hobbes afirma que el conocimiento de la proposición "yo pienso" lo adquirimos "al no poder concebir ningún acto sin su sujeto", 8 y esto significa, para este filósofo, que el acto tiene que atribuírsele a algo material. Así pues, cuando agrega que

3 Ibid.

4 A. Kenny, Descartes, Random House, Nueva York, 1968, p. 76; E.M. Curley, Descartes Against the Skeptics, Harvard University Press, Cambridge, 1978, p. 182; A. Kemmerling, "Eine reflexive Deutung des Cogito", en Theorie der Subjektivität, Suhrkamp, Francfort del Meno, 1990, sec. 141.

5 AT, VII, p. 175; AT, LX, p. 136; p. 143 (Alf).

6 A. Kenny, op. cit., p. 76.

7 AT, VII, p. 172; AT, IX, p. 134; p. 140 (Alf.).

8 AT, VII, p. 173; AT, IX, p. 135; p. 141 (Alf.). 
"no es mediante otro pensamiento por el que infiero que pienso", parece decir que la acción de pensar no debe atribuírsele a otro pensamiento, es decir, que no puede ser concebido como sujeto de esa acción, pues entonces aparece el regreso antes mencionado.

Precisamente por haber tomado Hobbes la objeción del regreso como una razón por la cual un pensamiento no puede atribuírsele a otro, Descartes pudo pasarla por alto. En las sextas objeciones nos encontramos con un caso semejante. También aquí el regreso es utilizado para apoyar otra objeción.

Para estar seguro de que pensáis, debéis saber antes cuál es la naturaleza del pensamiento y de la existencia; y, mientras ignoráis ambas cosas icómo podéis saber que pensáis o que existís? Así pues, al decir yo pienso, no sabéis qué decís, y al añadir luego existo, tampoco lo entendéis; y ni siquiera sabéis si decís o pensáis algo, siendo necesario para ello que sepáis que sabéis qué decís, y para esto, a su vez, que sepáis que sepáis que sabéis qué decís, y así hasta el infinito; por lo tanto, es evidente que no podéis saber si existís, y ni siquiera si pensáis. ${ }^{9}$

También en esta objeción podemos distinguir dos partes. La primera dice que no podemos saber que pensamos, si no poseemos un saber previo acerca de lo que es pensar. La segunda, que no podemos saber que pensamos, porque para ello tendríamos que saber que sabemos qué es pensar, etc. La primera parte es una objeción correcta en contra del cogito, si tomamos en cuenta que al postular el cogito, Descartes ha puesto en cuestión todos los conocimientos previos, y esto significa para los autores de las sextas objeciones que no tiene a su disposición el conocimiento que le permitiría identificar su actividad como pensamiento. La segunda parte, en la cual encontramos el regreso, tendría que venir a reforzar la primera observación, pero justo al usar el regreso de esta manera, se le deforma, perdiendo así su fuerza. Parece como si los autores de esta objeción manejaran las expresiones "saber que..." y "saber qué..." como si fueran equivalentes. Está claro que exigimos saber que pensamos para poder aceptar la proposición "pienso", también podemos exigir saber que sabemos que pensamos. Pero esto es diferente a exigir saber que sabemos qué es pensar. Al exigir esto último no argumentamos en contra de la posibilidad de identificar nuestra actividad como pensar, cuando no tenemos un conocimiento previo de lo que es el pensar, sino en contra de la posibilidad de poseer un conocimiento, por el cual podamos identificar nuestra actividad como pensar. Este problema, sin embargo, no le atañe en particular a la formulación del cogito, sino a la posibilidad del conocimiento en general, a lo cual hace alusión Descartes, cuando señala en su refutación que un saber como ése, que conduce a un

9 AT, VII, p. 413; AT, IX, p. 218; p. 315 (Alf.). 
regreso al infinito, "no es posible, sea cual sea la cosa sobre la que verse". Esto es prácticamente lo único que dice Descartes acerca de este regreso en su respuesta, la cual se concentra fundamentalmente en la primera parte de la objeción.

Es muy cierto que nadie puede estar seguro de que piensa ni de que existe, si antes no conoce la naturaleza del pensamiento y la existencia. Ahora bien, no es menester para ello un saber reflexivo, o adquirido por demostración, y mucho menos el saber de ese saber, mediante el cual sepa que sabe, y sepa que sabe que sabe, y así hasta el infinito, pues un conocimiento tal es imposible, sea cual sea la cosa sobre la que verse; basta con saber eso mediante ese género de conocimiento interior que antecede siempre al reflexivo y que es innato a los hombres por lo que toca al pensamiento y a la existencia [... ] Así pues, cuando alguien se da cuenta de que piensa, y concluye de ahí, con toda evidencia, que existe, aunque acaso no se haya tomado nunca el trabajo de saber qué es el pensamiento ni la existencia, las conoce por fuerza lo bastante como para que no le quede duda alguna al respecto. ${ }^{10}$

En virtud de la ocurrencia de la expresión "saber reflexivo" podría pensarse que Descartes rechaza en el cogito la conciencia del pensar, lo cual estaría en franca contradicción con la última oración del pasaje antes citado ("Así pues, cuando alguien se da cuenta de que piensa,..."). Es, pues, necesario explicar lo que Descartes entendía por reflexión. Para ello podemos remitirnos a la correspondencia con Arnauld.

En su carta de julio de 1648 Arnauld $^{11}$ exhorta a Descartes a explicar en qué consiste la reflexión, de la cual, conforme a su interpretación, depende el recuerdo. Esta exhortación presupone, por un lado, la siguiente afirmación de Descartes en sus respuestas a las objeciones de Arnauld: "no me cabe duda de que el espíritu, tan pronto como es infundido en el cuerpo de un niño, comienza a pensar, y desde ese mismo momento es consciente de que piensa, aunque después no recuerde lo que ha pensado", ${ }^{12}$ por êl otro, la explicación que da en su carta a Arnauld del 4 de junio de $1648,{ }^{13}$ en la que afirma que el niño no recuerda lo que ha sentido en el seno materno, porque aún no es capaz de llevar a cabo la reflexión que exige el recuerdo. En su respuesta a esta exhortación Descartes caracteriza la reflexión de la siguiente manera:

10 AT, VII, p. 422; AT, IX, p. 225-226; p. 323 (Alf.).

11 AT, V, p. 213; Descartes, en G. Lewis (ed.), Correspondance avec Arnauld et Morus, trad. de Clerselier, J. Vrin, París, 1953, p. 79.

12 AT, VII, p. 246; AT, IX, p. 190; p. 198 (Alf.).

13 AT, V, p. 193; Descartes, op. cit., p. 71. 
Cuando un adulto siente algo nuevo y simultáneamente se percata que no lo ha sentido hasta entonces, llamo a esta percepción una reflexión y la remito sólo al entendimiento, no obstante estar de tal manera vinculada a la sensación, que se producen simultáneamente y no parecen distinguirse. ${ }^{14}$

De acuerdo con esta caracterización, la reflexión es una consideración acerca de un pensamiento actual, que, sin embargo, toma en cuenta nuestras experiencias anteriores y que se distingue del pensamiento que enfoca. Ahora se entiende por qué Descartes, en su respuesta a las sextas objeciones, coloca el "saber adquirido por demostración" al lado del "saber reflexivo": por este último término Descartes entiende el conocimiento adquirido por experiencia, de tal suerte que al colocarlo al lado del conocimiento adquirido por demostración, parece agregar a las dos fuentes del conocimiento generalmente reconocidas, a saber, experiencia y demostración, un tercer tipo de conocimiento, el "interno" que "antecede al reflexivo", es decir, a la experiencia. Cómo opera este conocimiento interno, es un problema que nos alejaría demasiado de nuestro objetivo. Lo importante aquí es destacar que la reflexión para Descartes no es autorreferencia ni conciencia del pensamiento presente. No puede ser autorreferencia ya que ha fijado con toda claridad la diferencia entre el pensamiento enfocado, que en este caso es incluso una sensación, y la reflexión que siempre es una acción del intelecto. Conciencia del pensamiento actual tampoco puede serlo, dado que Descartes ha exigido esta última del niño aún en el seno materno, tan pronto tengamos derecho a hablar de pensar, mientras que la reflexión la ha rechazado con respecto al mismo.

En la primera parte de este trabajo he intentado mostrar por qué Descartes no tomó en consideración la objeción del regreso dirigida en contra del cogito: porque fue insertada como apoyo a otra objeción, que Descartes podía refutar sin necesidad de enfrentarse al regreso. Si ahora queremos presentar la objeción del regreso al infinito de pensamientos, no debemos dirigirla en contra del cogito. Basta y ayuda a simplificar el asunto, el dirigirla en contra de la proposición "no puede haber en nosotros pensamiento alguno, del cual no tengamos conciencia en el momento mismo en que se da en nosotros", la cual tiene que valer también para el cogito.

Aceptemos que somos conscientes de nuestro pensar actual. El hecho de ser conscientes de nuestro pensar actual es también un pensar, de tal suerte que, de acuerdo con la proposición antes mencionada, tenemos que

14 AT, V, p. 221; Descartes, op. cit., p. 87. 
ser también conscientes del mismo. Pero, de esta manera se genera un nuevo pensamiento del cual tenemos que ser conscientes y así hasta el infinito. No podemos aceptar, pues, tal serie de pensamientos, que tiene que darse precisamente en el momento en que tenemos un pensamiento. Por lo tanto, no podemos ser conscientes de un pensamiento precisamente en el momento en que lo tenemos.

$\mathrm{Si}$ atendemos a la traducción del término sum conscius por savoir en la versión francesa de las Objeciones a las meditaciones metafísicas, ${ }^{15}$ podríamos presentar la objeción del regreso de la siguiente manera: no podemos saber que ahora pensamos, porque de aquí se sigue, de acuerdo con la proposición antes mencionada, que sabemos que sabemos que pensamos y así hasta el infinito.

Esta objeción es correcta en la medida en que Descartes maneja indistintamente los conceptos de conscientia y cogitatio, lo cual se ve claramente en las refutaciones a las terceras objeciones: "Hay [...] actos que llamamos del pensamiento [cogitativos] como entender, querer, imaginar, sentir, etc., los cuales coinciden entre sí en presuponer el pensamiento, la percepción o la conciencia." 16

Si ahora tomamos en cuenta que en la sexta meditación Descartes determina la esencia del pensamiento como intelecto ${ }^{17}$ y en los Principios de la filosofía caracteriza la perceptio como una operación intelectual, ${ }^{18}$ entonces podemos decir que la conciencia es para él una operación intelectual. Si así fuera, entonces tendríamos que entender por "conciencia" en la proposición "no puede haber en nosotros pensamiento alguno, del cual no tengamos conciencia" una reflexión, un acto del intelecto que enfoca otro pensamiento. En este sentido, tiene razón Curley cuando al considerar la discusión antes mencionada entre Arnauld y Descartes afirma: "If we held that consciousness must evolve reflective thought, then it would become very obscure just what the sense is in which an infant might be said to be conscious of its pleasures and pains." 19 Pero, la conciencia genera pensamiento reflexivo en Descartes, sólo en la medida en que deja coincidir cogitatio, conscientia y perceptio, lo cual no sucede en todos los casos, como atinadamente señala Kenny: "Sometimes, consciousness appears to be something which accompanies thought (as in the Second Replies); sometimes it appears to be something which is identical with thought."20

15 AT, IX, p. 190.

16 AT, VIl, p. 176; AT, IX, p. 137; p. 143 (Alf.).

17 AT, VII, p. 78-79; AT, IX, p. 62; p. 66 (Alf.).

18 AT, VIII, p. 17; AT, IV, p. 39.

19 E.M. Curley, op. cit., p. 181.

20 A. Kenny, The Anatomy of the Soul, B. Blackwell, Oxford, 1973, p. 117. 
Precisamente en las dos definiciones que Descartes nos ofrece acerca del pensamiento se evita esta coincidencia. En las Rationes, que se encuentran integradas a las respuestas a las segundas objeciones, leemos:

Con el nombre de pensamiento, comprendo todo lo que está en nosotros de modo tal, que somos inmediatamente conscientes de ello. Así, son pensamientos todas las operaciones de la voluntad, del entendimiento, de la imaginación y de los sentidos. ${ }^{21}$

En el 19 de la primera parte de los Principios:

Por pensamiento comprendo todo lo que sucede en nosotros de tal manera que somos inmediatamente conscientes de ello; por eso, no sólo entender, querer, imaginar, sino también sentir, son lo mismo que pensar. ${ }^{22}$

Es cierto que en ambos casos el pensamiento se define de manera que su alcance parece coincidir con el de la conciencia, pero si observamos con más cuidado el asunto, sólo podemos decir que el campo de la aplicación de la conciencia coincide con la extensión del pensamiento (no podemos afirmar que el conjunto de todos los pensamientos es el mismo que el conjunto de todos los actos de la conciencia). Pues bien, si nos atenemos estrictamente a la diferencia establecida entre conciencia y pensamiento, la objeción del regreso al infinito de pensamientos se anula, pues entonces la conciencia no cae en el alcance de la proposición: "no puede haber en nosostros pensamiento alguno, del cual no tengamos conciencia". Esta diferencia entre pensamiento y conciencia me parece el único medio para evitar la objeción del regreso. Pero la consecuencia de esta solución es el rechazo de la autoconciencia en sentido estricto, ya que, en la medida en que el pensamiento es definido como objeto inmediato de la conciencia, tan pronto como se vuelve objeto de sí misma, cae en el campo del pensamiento y se desencadena el regreso. Por ello, para la filosofía cartesiana la conciencia de algo no puede ser también conciencia del ser consciente de ese algo.

La interpretación anterior de la conciencia evita el regreso y salva así la proposición, contra la cual habla el regreso, sin embargo, se opone a la afirmación más general de Descartes, según la cual "nada puede haber en nuestro espíritu, en cuanto es una cosa pensante, de lo cual nuestro espíritu no sea consciente". ${ }^{23}$ 